\title{
Displacement Based Design Optimization of Steel Moment Frames
}

\author{
GHAZI ARSLAN AHMED*, AND FAISAL SHABBIR* \\ RECEIVED ON 17.05.2017 ACCEPTED ON 21.08.2017
}

\begin{abstract}
Optimization of steel moment resisting frames considering the displacement as the fundamental element is the main aim of the present study. DDBD (Direct Displacement Based Design) methodology have been used for the subject purpose. This design methodology have been developed to cater for the shortcomings in the current FBD (Force Based Design) methodology that is in practice. Steel moment frame have been analyzed and designed with both FBD and DDBD methodologies. Strength constraints imposed by AISCLRFD (American Institute of Steel Construction Load and Resistance Factor Design) and maximum allowable displacement constraints set forth by the FEMA-356 (Federal Emergency Management Agency) against the different performance levels are checked during the optimization process. Load combinations selected are in accordance with ASCE 7-05 (American Society for Civil Engineers) Numerical example presented exhibit the advantages of DDBD over FBD methodology. It was observed that the drift experienced by the structure designed according to DDBD varies more uniformly with height as compared to FBD.
\end{abstract}

Key Words: Steel Moment Resisting Frames, Direct Displacement Based Design, Structural Optimization, Non-Linear Static Analysis.

\section{INTRODUCTION}

$\mathrm{L}$ arge number of design parameters affect the performance of the structural system based on seismic design considerations. Material cost is an important aspect in building construction. Minimizing the weight of structural elements unfolds economical structures but at the same time structural stability and soundness is required to be ensured under the extreme loading conditions especially earthquakes. This is a key apprehension in the field of structural engineering. In order to address such apprehensions structural optimization methodologies have been developed. Many researchers have introduced the PBD (Performance Based Design) methodology, which is rational approach to achieve specific structural performance objectives, in combination with the algorithms. Gholizadeh and Ebadijalal [1] proposed PBD methodology for steel frames in accordance with design codes by employing SECBO (Sequential Enhanced Colliding Bodies Optimization) algorithm. Deng and Suresh [2] proposed a procedure for solving multi-constrained 3D (Three Dimensional) topology optimization problems. The suggested methodology is an amalgamation of the topological levelset invention, improved Lagrangian algorithm, and traditional FEA(Finite Element Analysis). Bruno et. al. [3] proposed a unique design methodology by for arch bridges by implementing a three step optimization 
algorithm with finite element model. Papavasileiou et. al. [4] used the discrete evolution strategies algorithm for the seismic optimization of multi-storey composite buildings .

DDBD methodology is an area attracting enormous interest at present time. DDBD characterizes the structure to be designed by a SDOF (Single Degree of Freedom) representation of performance at peak displacement response, rather than by its initial elastic characteristics [5]. This is based on Substitute Structure approach pioneered by others [6-7]. Structures designed by this approach would fulfill the performance limit state in accordance with the assigned seismic intensity. The design method defines the design strength at the selected plastic hinge locations to attain the distinct displacement objectives. Contrary to DDBD, the assumptions were made about the member sizes and their stiffness before the design seismic forces are determined in FBD. Consequently, if the member sizes are modified from the initial assumption, then the calculated design force will no longer be valid, and recalculation, though rarely carried out is theoretically required. Furthermore, the design under such methodology exhibit the elastic characteristics of the structure which no longer remains as soon as the structural behavior changes from elastic to plastic mode. Under such circumstances in order to meet the safety and serviceability criteria the designed structure will be uneconomical and will comprise of large member sizes than actually required. The extent of economic impact will be more as the seismic performance requirements change from low to high.

In order to overcome such limitations and to opt for optimal structure design FBD should be replaced with more advanced, best equipped and intellectually satisfying DDBD methodology. In present study numerical example of planar steel moment frame structure have been used. Both the methods have been used to design the steel moment resisting frame. First of all the design criteria consisting of parameters and constraints are finalized, then the structure is analyzed by FBD using NSLFP (NonLinear Static Lateral Force Procedure) to comply with the target displacements and drift limits for different performance levels according to FEMA-356 [8]. The load combinations used for analysis is in accordance with ASCE 7-05 [9]. Forces obtained by analysis are used to design the structure keeping the compliance with the design criteria. The analysis and design for FBD has been done by the aid of structural analysis and design software Etabsv 9.7 [10]. Optimization is done manually through employing DDBD approach for analysis and design in accordance with the selected criteria and complying the assigned constraints. The reference structure along with the design parameters for preliminary analysis process is selected as proposed in performance based design optimization of steel moment frames [11]. In the present paper attempt is made to recommend dependable design measures for seismic design of regular steel momentresisting frames within the defined performance levels. The contribution of current study is that the three different optimized designs are obtained which are suited to the three performance levels as defined by FEMA-356 [8].

\section{DISPLACEMENT BASED OPTIMIZATION METHODOLOGY}

The proposed structure in performance based design optimization of steel moment frames by [11] is taken as basic structure. The reason is that we believe that the selected structure is good starting point for this study. Furthermore, we are interested to know that how much more optimized solution is possible with the subject structure. Initially, the selected structure is evaluated for capacity design against the non-seismic gravity load combinations as per the load combinations of ASCE 7-05. If the design is satisfied, then inter-story drift is

Mehran University Research Journal of Engineering \& Technology, Volume 37, No. 3, July, 2018 [p-ISSN: 0254-7821, e-ISSN: 2413-7219] 
investigated. After that the optimization is done manually by employing DDBD methodology considering three limit states defining required performance levels. Following procedure is adopted for the investigation in current study.

\subsection{FBD Methodology}

The specified performance level indicating hazard frequency is defined first. This is done by selecting the structure performance level. For current study performance levels in accordance with FEMA-356 are categorized as IO (Immediate Occupancy), LS (Life Safety) and CP (Collapse Prevention). Each performance function denotes a certain level of seismic hazard which has 20, 10 and $2 \%$ probability of exceedance in 50 years return period. After the hazard and performance function definition analysis is conducted employing NSLFP to evaluate the non-linear seismic response against the selected earthquake hazard. FEMA-356 outlines various methods but the one which deals with the considerations for displacements [8] is used. The structure is pushed up to the objective displacement by the application of monotonically increased lateral loads to evaluate the storey drifts. Lateral loads are calculated in accordance with ASCE 7-05. The objective displacement is defined by FEMA-356 by Equation (1).

$\delta_{\mathrm{t}}=\mathrm{C}_{0} \mathrm{C}_{1} \mathrm{C}_{2} \mathrm{C}_{3} \mathrm{~S}_{\mathrm{a}}\left(\frac{\mathrm{T}_{\mathrm{e}}^{2}}{4 \mathrm{JJ}^{2}}\right) \mathrm{g}$

Where $\mathrm{C}_{\mathrm{o}}$ is spectral displacement coefficient related to roof displacement, $\mathrm{C}_{1}$ is the coefficient which relates the maximum inelastic displacement to the linear elastic displacement, $\mathrm{C}_{2}$ is coefficient to represent the pinched hysteretic shape, stiffness degradation and strength deterioration on maximum displacement, $\mathrm{C}_{3}$ is modification coefficient for increased P-delta effects, $\mathrm{S}_{\mathrm{a}}$ response spectrum acceleration against effective period $\mathrm{T}_{\mathrm{e}}$ and $\mathrm{g}$ is acceleration due to gravity.

\subsection{DDBD Methodology}

Contrary to FBD processes, DDBD methods emphasis is to control objective displacements of the subject structure. Subsequently it is easy to measure the destruction in terms of displacements rather than the forces, this method targets the structure design that represents a predetermined maximum objective displacement. The main steps of DDBD procedure as proposed by Priestley et. al. [5] are briefly illustrated in the proceeding paragraphs.

Based on the determined performance levels objective displacement is determined which serves as a basis for the determination of inelastic mode shape. Then the MDOF (Multi-Degree of Freedom) system is substituted to the corresponding SDOF system. After that the effective mass $\left(m_{e}\right)$, the effective height $\left(\mathrm{H}_{\mathrm{e}}\right)$ and the design displacement $\left(\Delta_{d}\right)$ are calculated. In the next step displacement ductility demand $\mu$ for SDOF system is calculated as $\mu=\Delta_{\mathrm{d}} / \Delta_{\mathrm{y}}$. Where $\Delta_{\mathrm{d}}$ is design displacement or objective displacement and $\Delta_{\mathrm{y}}$ is the yield displacement which is a product of yield drift $\theta_{y}$ and effective height $\mathrm{H}_{\mathrm{e}}$ and can be calculated as $\Delta_{\mathrm{y}}=\theta_{\mathrm{y}} \mathrm{H}_{\mathrm{e}}$.

The yield drift in terms of steel strain $\varepsilon_{y}$, beam length $L_{b}$ and beam depth $h_{b}$ for steel frames is given as $\theta_{y}=0.65 \varepsilon_{y}$ $\mathrm{L}_{\mathrm{b}} / \mathrm{h}_{\mathrm{b}}$. Conversely, the effective viscous damping as a function of design displacement ductility demand is given as $\xi_{\text {eq }}=0.05+0.577(\mu-1 / \mu \Pi)$. Equivalent viscous damping calculated will be used to obtain the elastic displacement spectrum. Based on the calculated elastic spectrum with the design displacement, the effective period $\left(\mathrm{T}_{\mathrm{e}}\right)$ of the ancillary SDOF structure can be obtained. This effective period is used to calculate the effective system stiffness $\left(\mathrm{K}_{\mathrm{e}}\right)$ and base shear $\left(\mathrm{V}_{\text {base }}\right)$ ). The base shear $\left(\mathrm{V}_{\text {base }}\right)$ is then dispersed over the height of the structure as a function of lateral forces relative to the expected lateral displacement shape and to the floor masses by $F_{i}=V_{\text {base }}$ $\mathrm{m}_{\mathrm{i}} \Delta_{\mathrm{i}} / \sum_{\mathrm{i}=1}^{\mathrm{n}}\left(\mathrm{m}_{\mathrm{i}} \Delta_{\mathrm{i}}\right)$. 
The analysis under the distributed storey lateral forces calculated is carried out to determine the mandatory flexural capacity at the plastic hinge localities. Gravity load moments are not added to these seismic moments as this will result in the increased cost of the structure and secondly, such action will reduce the seismic response displacement below the projected design intensities. The gravity and seismic beam moments should be compared and larger is adopted for the detailing and design of plastic hinge.

The member strength capacities are finally calculated using an equilibrium approach.

\section{ANALYSIS AND DESIGN}

In the present study during the optimization two constraints are of prime importance. First involves the investigation of strength capacity of elements against the combined action of compression and flexure according to AISC-LRFD [12] by Equations (2-3).

$$
\begin{aligned}
& \text { For } \frac{\mathrm{P}_{\mathrm{u}}}{\phi c \mathrm{P}_{\mathrm{n}}}<0.2:\left(\frac{\mathrm{P}_{\mathrm{u}}}{2 \phi \mathrm{P}_{\mathrm{n}}}+\frac{\mathrm{M}_{\mathrm{u}}}{\phi b \mathrm{M}_{\mathrm{n}}}\right) \leq 1 \\
& \text { For } \frac{\mathrm{P}_{\mathrm{u}}}{\phi c \mathrm{P}_{\mathrm{n}}} \geq 0.2:\left(\frac{\mathrm{P}_{\mathrm{u}}}{2 \phi \mathrm{P}_{\mathrm{n}}}+\frac{\mathrm{M}_{\mathrm{u}}}{\phi b \mathrm{M}_{\mathrm{n}}}\right) \leq 1
\end{aligned}
$$

Where $\mathrm{P}_{\mathrm{u}}$ is the required axial strength, $\mathrm{P}_{\mathrm{n}}$ is the nominal axial strength, $\phi_{\mathrm{c}}$ is the resistance factor, $\mathrm{M}_{\mathrm{u}}$ is the required flexure strength, $M_{n}$ is the required nominal flexure strength and $\phi_{\mathrm{b}}$ is the flexural resistance reduction factor (AISC, 2001) [12].

Non-seismic load combinations as per ASCE 7-05 will be used for investigation of strength constraints and are stated in Equation (4)

$\mathrm{W}_{\mathrm{u}}=1.2 \mathrm{~W}_{\mathrm{d}}+1.6 \mathrm{~W}_{1}$
Where $\mathrm{W}_{\mathrm{u}}$ is factored gravity load, $\mathrm{W}_{\mathrm{d}}$ is the gravity dead load and $\mathrm{W}_{1}$ is gravity live load.

Second constraint is the allowable storey drift against the limit states defining performance levels as IO, LS, and $\mathrm{CP}$ as per FEMA-356 requirements.

As per ASCE (7-05) load combinations in conjunction with seismic loads are used for the investigation of storey drift is given by Equation (5)

$\mathrm{W}_{\mathrm{u}}=1.3 \mathrm{~W}_{\mathrm{d}}+1.0 \mathrm{~W}_{1}+1.0 \mathrm{~W}_{\mathrm{eq}}$

In case the above mentioned constraints are not satisfied revision in member sizes is required, otherwise structure is evaluated for the lateral load using (NSLFP) and designed accordingly. After that the optimization is done by employing DDBD.

During the optimization capacity design requirements should be fulfilled for the frame members. This is done by considering the over strength factor $\phi^{\circ}$, and the dynamic amplification factor $\omega$ for the appropriate design action. This can be explained by aid of Equation (6).

$\phi_{\mathrm{S}} \mathrm{S}_{\mathrm{D}} \geq \mathrm{S}_{\mathrm{R}}=\phi^{0} \omega \mathrm{S}_{\mathrm{E}}$

Where $S_{E}$ is the capacity protected design action due to lateral force distribution as a result of DDBD procedure, $\mathrm{S}_{\mathrm{D}}$ is the nominal capacity governing design strength and $\phi_{\mathrm{S}}$ is the strength reduction factor.

\section{NUMERICAL RESULTS}

One way 6-storey planar steel frame is optimized in this section. All the design parameters are the same as mentioned by Gholizadeh and Ebadijalal [11]. The frame is assumed to have rigid connections and fixed supports. All member are selected from $267 \mathrm{~W}$-shaped sections from AISC database. The value of the modulus of elasticity is $210 \mathrm{GPa}$ and steel yield stress is $235 \mathrm{MPa}$. Strain hardening 
slope of 3\% is adopted for this study. Maximum storey drift as per FEMA requirements for IO, $\mathrm{LS}$ and $\mathrm{CP}$ is taken as $0.7,2$ and $2.5 \%$ of the storey height. Dead load $\left(Q_{d}\right)$ on all beams is $24.5 \mathrm{KN} / \mathrm{m}$ and live load $\left(\mathrm{Q}_{1}\right)$ is $9.8 \mathrm{KN} / \mathrm{m}$. Response Modification Factor R for steel SMRF is taken as 8 and the site class is taken as D. Site parameters related to class $\mathrm{D}$ against the defined hazard levels as defined by FEMA-356 are given in Table 1.

\subsection{Six Storey Steel SMRF}

Fig. 1 is the geometry and the elements details. The frame consists of three equal bays of length $5 \mathrm{~m}$ and six stories with a typical storey height of $3 \mathrm{~m}$. The frame comprises of 6 beams and 12 column groups. The columns are grouped as external and internal columns. The external columns are grouped story wise starting from $\mathrm{C} 1-\mathrm{C} 6$ while the internal columns are grouped as $\mathrm{C} 7-\mathrm{C} 12$. Similarly, the beams are also grouped story wise starting from B1at storey-1 to B6 at top storey.

\section{RESULTS AND DISCUSSION}

The investigation started by selecting the structure topology along with the design parameters stated in the performance based design of steel moment fames by Gholizadeh and Ebadijalal [11]. The motive behind such selection is that firstly, in our opinion it provides good basis for the preliminary design process. Secondly, we want to know the efficiency of DDBD as an optimization tool for structural designing. After the topology selection the strength capacity of the selected members by the application of Equations (2-3) against the non-seismic gravity load combination is investigated. Then, the seismic demands of the structure in accordance with the drift limits against the specified performance levels are determined by using NSLFP keeping in view the seismic load combination of Equation (5). The design is then optimized in the light of the analysis results.

After that process the optimization was done through DDBD. In order to acquire the optimal design DDBD methodology is employed and the structure is redesigned using DDBD guidelines. Initially the structure consisting of preliminary topology is analyzed using DDBD. The results are scrutinized for further optimization. This task is achieved by performing iterations until best possible solution in compliance with the design constraints is achieved. The analysis and design is terminated and the solution obtained is presented as the final possible optimal solution. As three different performance levels for the

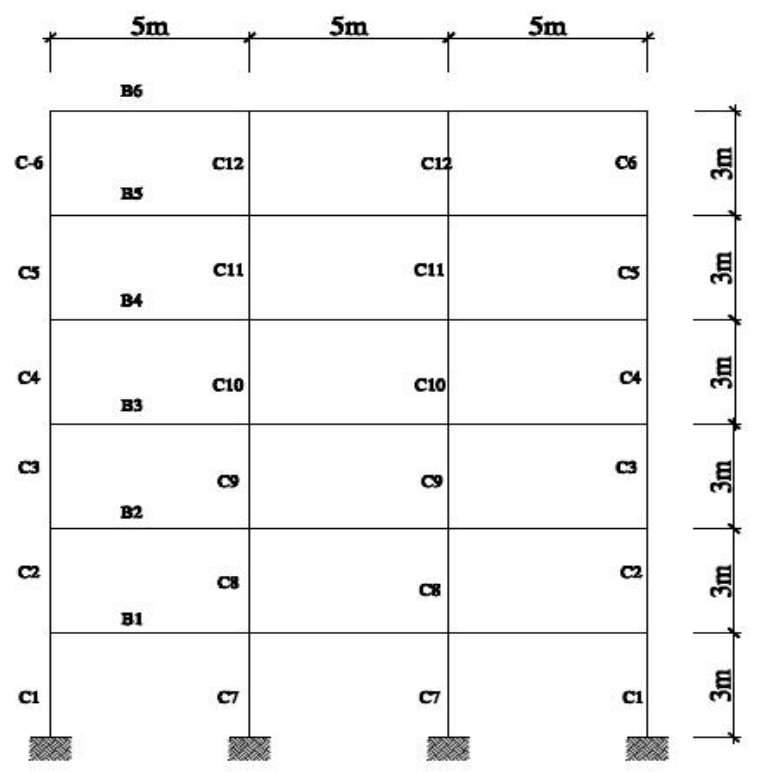

FIG. 1. STRUCTURE GEOMETRY

TABLE 1. SITE PARAMETERS OF DIFFERENT PERFORMANCE LEVELS FOR CLASS D

\begin{tabular}{|c|c|c|c|c|c|}
\hline Performance Levels & Hazard Levels & $\mathrm{SS}(\mathrm{g})$ & $\mathrm{S} 1(\mathrm{~g})$ & $\mathrm{Fa}$ & Fy \\
\hline $\mathrm{IO}$ & $20 \% / 50$ years & 0.658 & 0.198 & 1.27 & 2.00 \\
\hline LS & $10 \% / 50$ years & 0.794 & 0.237 & 1.18 & 1.92 \\
\hline $\mathrm{CP}$ & $2 \% / 50$ years & 1.150 & 0.346 & 1.04 & 1.70 \\
\hline
\end{tabular}

Mehran University Research Journal of Engineering \& Technology, Volume 37, No. 3, July, 2018 [p-ISSN: 0254-7821, e-ISSN: 2413-7219] 
structure under consideration are selected. This yields three different structural design solutions against them. The optimal design results along with the preliminary design resulting from both NSLFP and DDBD are presented Table 2

All the member sizes mentioned in Table 2 are investigated for the strength constraints and the drift limitations. For the NSLFP three different types of designs are obtained for IO, LS and CP performance levels. This approach is being widely practiced and has some drawbacks especially towards the seismic performance as well as the economy of the project. Considering the seismic performance levels NLSFP design exhibits less ductility demand as a result of which the structure dissipates less energy and experiences more effect of seismic base shear. More importantly the non-linear behavior is not properly evident. Such type of structures are mostly avoided as they fail in brittle mode. As the main objective of the current study is to highlight the effectiveness of the DDBD in optimization effort, therefore, DDBD design against the three selected performance levels namely IO, LS and CP is also proposed and tabulated in Table 2.

TABLE 2. OPTIMUM DESIGN SOLUTIONS

\begin{tabular}{|c|c|c|c|c|c|c|c|c|c|}
\hline \multicolumn{3}{|c|}{ Optimal Designs } & \multirow{2}{*}{$\frac{\text { Preliminary }}{\mathrm{IO}}$} & \multicolumn{3}{|c|}{ NSLFP } & \multicolumn{3}{|c|}{ DDBD } \\
\hline No. & Description & Label & & IO & LS & $\mathrm{CP}$ & IO & LS & $\mathrm{CP}$ \\
\hline 1. & \multirow{6}{*}{ Beam } & B1 & W18X60 & W18X60 & W18X55 & W18X50 & W24X76 & W18X40 & W16X36 \\
\hline 2. & & B2 & W18X60 & W18X60 & W18X55 & W18X50 & W24X55 & W18X40 & W16X36 \\
\hline 3. & & B3 & W18X46 & W18X46 & W18X40 & W18X40 & W21X44 & W18X35 & W16X31 \\
\hline 4. & & B4 & W18X46 & W18X46 & W18X40 & W18X40 & W21X44 & W18X35 & W16X31 \\
\hline 5. & & B5 & W16X31 & W16X31 & W16X31 & W16X31 & W18X40 & W18X35 & W14X26 \\
\hline 6. & & B6 & W16X31 & W16X31 & W16X31 & W16X31 & W16X36 & W18X35 & W14X26 \\
\hline 7. & \multirow{12}{*}{ Column } & $\mathrm{C} 1$ & W21X44 & W21X44 & W21X44 & W21X44 & W18X35 & W18X35 & W18X35 \\
\hline 8. & & $\mathrm{C} 2$ & W21X44 & W21X44 & W21X44 & W21X44 & W18X35 & W18X35 & W18X35 \\
\hline 9. & & $\mathrm{C} 3$ & W18X35 & W18X35 & W18X35 & W18X35 & W18X35 & W18X35 & W18X35 \\
\hline 10. & & $\mathrm{C} 4$ & W18X35 & W18X35 & W18X35 & W18X35 & W16X26 & W16X26 & W16X26 \\
\hline 11. & & $\mathrm{C} 5$ & W16X31 & W16X31 & W16X31 & W16X31 & W14X22 & W14X22 & $\mathrm{W} 14 \mathrm{X} 22$ \\
\hline 12. & & $\mathrm{C} 6$ & W16X31 & W16X31 & W16X31 & W16X31 & W12X14 & W12X14 & W12X14 \\
\hline 13. & & $\mathrm{C} 7$ & W18X55 & W18X55 & W18X55 & W18X55 & W24X55 & W24X55 & W24X55 \\
\hline 14. & & $\mathrm{C} 8$ & W18X55 & W18X55 & W18X55 & W18X55 & W24X55 & W24X55 & W24X55 \\
\hline 15. & & C9 & W18X50 & W18X50 & W18X50 & W18X50 & W24X55 & W24X55 & W24X55 \\
\hline 16. & & $\mathrm{C} 10$ & W18X50 & W18X50 & W18X50 & W18X50 & W21X44 & W21X44 & W21X44 \\
\hline 17. & & $\mathrm{C} 11$ & W18X35 & W18X35 & W18X35 & W18X35 & W18X35 & W18X35 & W18X35 \\
\hline 18. & & $\mathrm{C} 12$ & W18X35 & W18X35 & W18X35 & W18X35 & W14X22 & W14X22 & $\mathrm{W} 14 \mathrm{X} 22$ \\
\hline \multicolumn{3}{|c|}{ Total Weight (KN) } & 169.48 & 169.48 & 167.68 & 165.49 & 159.30 & 143.05 & 135.55 \\
\hline
\end{tabular}


Results from Table 2 clearly indicate the effectiveness of DDBD in optimizing the structural design process in terms of optimal weight of the structure as compared to NSFP against the different performance levels.

Structural weights for IO, LS and CP designed with NSLFP and DDBD are shown in Table 3.

It can be seen that the structure designed by DDBD for IO, LS and CP is 6.0715 .2 and $18.1 \%$ lighter than the NSLFP. This argument is presented by the aid of Fig. 2 .

From Fig. 2 it can be deduced that the design obtained by DDBD against IO, LS and CP is in accordance with the defined performance levels individually. It was also found during the design process that the drift constraints regarding the pre-defined performance level comes out to be a critical factor. Out of the three performance levels IO controls the design process and most designers tend to opt for IO performance level design but as per FEMA-356 guidelines LS and CP performance levels can also be considered for design of structures. It can be seen that in case of DDBD the drift ratio decreases with the height of structure resulting in less drift at the top whereas, NSLFP design yields haphazard storey drift ratios. The sensitivity of drift constraints to both the design processes is shown in Figs. 3-5 which illustrates the storey drifts against IO, LS and CP performance levels.

From Figs. 3-5 it is self-evident that the variation of storey drifts along the height as per DDBD is much more uniform than NSLFP. This is because of the two reasons. Firstly, the lateral force distribution is also more uniform along the height of the structure. Secondly, the structure is detailed for plastic hinge mechanism in such a way that the yielding of bottom story beams control the sway of the structure. This results in more stiff lower level beams and consequently, less sway at the upper levels. Moreover, the limiting drifts against the specified performance level is considered at the start of the design process hence, the target displacement used for the design is based on drift limits. As a consequence, DDBD

TABLE 3. STRUCTURAL WEIGHTS FOR OPTIMIZED SOLUTIONS

\begin{tabular}{|c|c|c|c|}
\hline No. & Performance Level & $\begin{array}{c}\text { NSLFP } \\
(\mathrm{KN})\end{array}$ & $\begin{array}{c}\text { DDBD } \\
(\mathrm{KN})\end{array}$ \\
\hline 1. & IO & 169.48 & 159.30 \\
\hline 2. & LS & 167.68 & 143.05 \\
\hline 3. & CP & 165.49 & 135.55 \\
\hline
\end{tabular}

DDBD

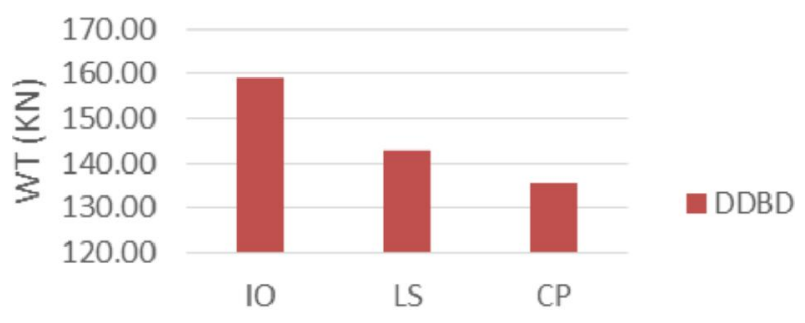

PERFORMANCE LEVELS
NSLFP

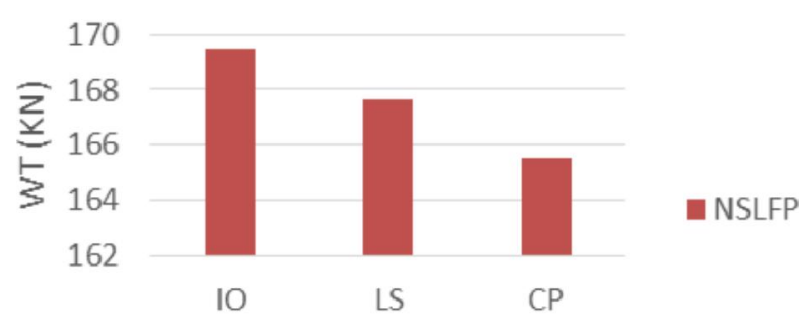

PERFORMANCE LEVELS

FIG. 2. OPTIMAL STRUCTURAL WEIGHTS AGAINST DIFFERENT PERFORMANCE LEVELS

Mehran University Research Journal of Engineering \& Technology, Volume 37, No. 3, July, 2018 [p-ISSN: 0254-7821, e-ISSN: 2413-7219] 
utilizes larger design displacement to address such concerns which results in higher ductility demand and greater equivalent viscous damping. By doing so the effect of seismic base shear on the structure reduces and this results in optimal design solutions by DDBD over FBD.

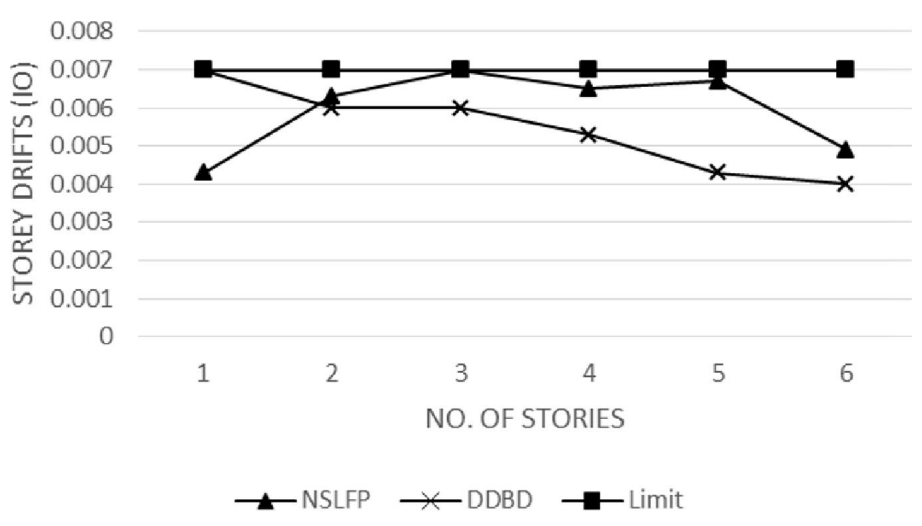

FIG. 3. STOREY DRIFTS FOR IO PERFORMANCE LEVEL

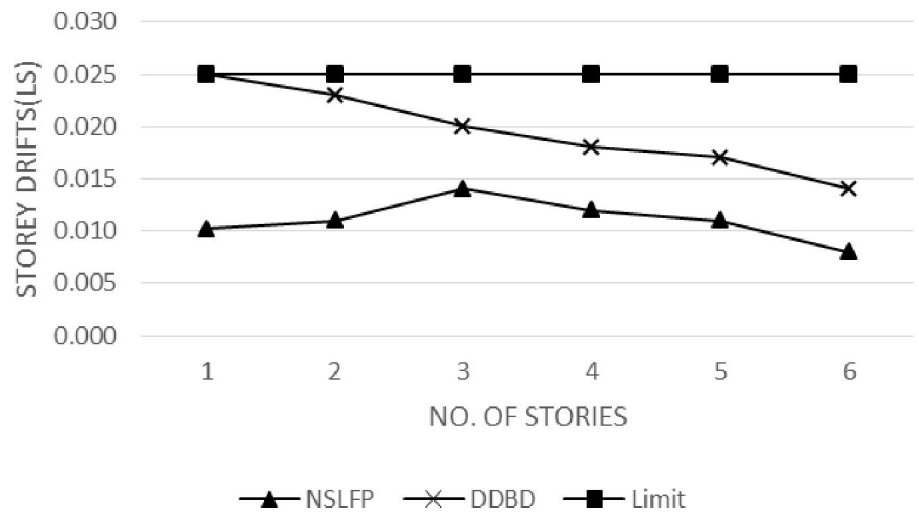

FIG. 4. STOREY DRIFT FOR LS PERFORMANCE LEVEL

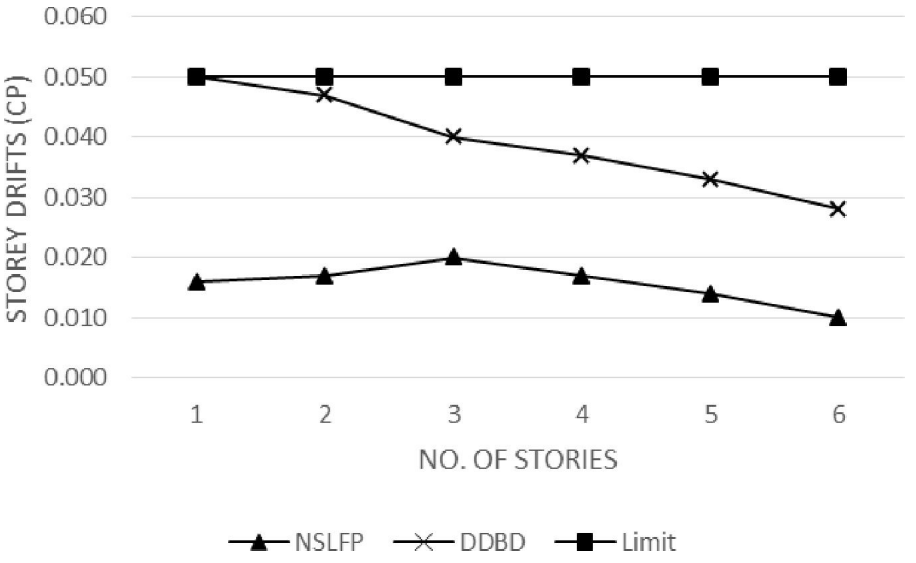

FIG. 5. STOREY DRIFT FOR CP PERFORMANCE LEVEL

Mehran University Research Journal of Engineering \& Technology, Volume 37, No. 3, July, 2018 [p-ISSN: 0254-7821, e-ISSN: 2413-7219] 
In author's point of view, the LS performance level DDBD design which is $15.2 \%$ lighter than NSLFP in terms of structural weight is recommended. LS level design warrants the repairable damage associated to the structural components which is far more important than the damage to non-structural components.

\section{CONCLUSIONS}

The present paper deals with the optimization of steel moment frames by employing DDBD methodology. Two constraints are investigated during the current study. In first type the storey drifts and displacements are checked to satisfy the FEMA-356 requirements. While the in second one deals with the strength capacity of the frame elements under the factored gravity loads according to AISC-LRFD. The load combinations are taken according to ASCE 7-05. It is practiced universally that IO performance level is taken as a reference for the structure design but this approach yields less stable designs in terms of performance levels. This is due to the fact that the design is less ductile due to which large sections are employed. This results in uneconomical solution as well. The numerical results of the above example clearly demonstrate that the solution proposed by employing DDBD method for IO, LS and CP is 6.07, 15.2 and 18.1\% lighter than the traditional force based method. The difference in the structure weight is due to the fact that the DDBD method details the plastic hinges in the structure in such a way that the energy is dissipated much more efficiently than FBD employing method. Also DDBD utilizes higher ductility demand and equivalent viscous damping due to which the effect of seismic base shear on the structure is minimized and as a result optimal design is obtained. Hence, DDBD method can be safely utilized to provide the optimal design solutions for the steel structures which can exhibit the intended design performance.

\section{ACKNOWLEDGEMENT}

The authors acknowledge to the Chairman, Department of Civil Engineering, University of Engineering \& Technology, Taxila, Pakistan, for his support throught this research.

\section{REFERENCES}

[1] Gholizadeh, S., and Ebadijalal, M., "Seismic Design Optimization of Steel Structures by A Sequential ECBO Algorithm", International Journal of Optimization in Civil Engineering, Volume 7, No. 2, pp. 157-170, Namrak, Tehran-1684613114, Iran, 2017.

[2] Deng, S., and Suresh, K., "Multi-Constrained 3D Topology Optimization via Augmented Topological Level Set", Computers \& Structures, Volume 170, Issue-C, pp. 1-12, July, 2016.

[3] Bruno, D., Lonetti, P., and Pascuzzo, A., "An Optimization Model for the Design of Network Arch Bridges", Computers \& Structures, Volume 170, Issue-C, pp. 13-25, July, 2016.

[4] Papavasileiou, S., and Champis, C., "Seismic Design Optimization of Multi-Storey Steel-Concrete Composite Buildings", Computers \& Structures, Volume 170, Issue-C, pp. 49-61, July, 2016.

[5] Priestley, M.J.N., Calvi, G.M., and Kowalsky, M.J., "Displacement Based Seismic Design of Structures", IIUS Press, Pavia, Italy, 2007.

[6] Gulkan, P., and Sozen, M., "Inelastic Response of Reinforced Concrete Structures to Earthquake Motions", Journal of the American Concrete Institute, Volume 71, No. 12, pp. 604-610, USA, 1974.

[7] Shibata, A., and Sozen, M., "Substitute Structure Method for Seismic Design in Reinforced Concrete", ASCE Journal of Structural Engineering, Volume 102, No. 1, pp. 1-18, USA, 1976.

[8] FEMA-356, "Pre-Standard and Commentary for Seismic Rehabilitation of Buildings", Federal Emergency Management Agency, Washington DC, USA, 2000.

Mehran University Research Journal of Engineering \& Technology, Volume 37, No. 3, July, 2018 [p-ISSN: 0254-7821, e-ISSN: 2413-7219] 
[9] ASCE/SEI 7-05, "Minimum Design Loads for Buildings and Other Structures", American Society for Civil Engineers, 1801 Alexander Bell Drive, Reston, VA 20191 USA, 2005

[10] Etabsv9.7, "Extended Three Dimensional Analysis of Building Systems", Computers and Structures Inc. University Ave, Berkeley, California, USA 94704, 1995.
[11]

Gholizadeh, S., Kamyab, R., and Dadshi, H., "Performance Based Design Optimization of Steel Moment Frames", International Journal of Optimization in Civil Engineering, Volume 3, No. 2, pp. 327-343, Namrak, Tehran-1684613114, Iran, 2012.

[12] AISC-LRFD, "Manual of Steel Construction, Load and Resistance Factor Design", American Institute of Steel Construction, Chicago-IL, 2001. 